\title{
La producción de combustibles ecológicos, un peligro para la seguridad alimentaria en Colombia*
}

\section{The production of ecological fuels, a danger for food security in Colombia}

Diana Plazas Santamaría**

Fecha de recepción: 4 de febrero de 2018

Fecha de aprobación: 10 de abril de 2018

\section{RESUMEN}

El presente trabajo tiene como propósito analizar el impacto que en la seguridad alimentaria de algunos territorios genera la producción a gran escala de la palma de aceite, utilizada a su vez para la producción de biocombustibles o combustibles ecológicos. Inicialmente, se realiza una amplia revisión de varias fuentes sobre las consecuencias de la siembra de la palma de aceite, su impacto ambiental, la utilización de las tierras para el efecto, el desplazamiento que su producción ha causado, su inclusión en los programas de gobierno y, finalmente, un análisis a la problemática alimentaria en Colombia a causa de la explotación de dicho insumo en la generación de biocombustibles. La anterior revisión detallada de diversas fuentes permitió establecer, que el auge de la siembra de la palma de aceite para la generación de combustibles ecológicos, pese a la generación de empleo y sus beneficios sobre la energía, también tiene consecuencias colaterales negativas que repercuten en la producción agrícola y de la cual se

* El presente documento es producto del proyecto de investigación: "La producción de combustibles ecológicos, un peligro para la seguridad alimentaria en Colombia”, gestionado en el marco de la Maestría en Derechos Humanos y Derecho Internacional de los Conflictos Armados DICA, en la Escuela Superior de Guerra, Bogotá D. C., Colombia. DOI: http://dx.doi.org/10.15332/s1909-0528.2018.0002.06

** Abogada de la Universidad Incca de Colombia, especialista en Derecho Administrativo y Constitucional de la Universidad Católica de Colombia, magíster en Derechos Humanos y Derecho Internacional de los Conflictos Armados de la Escuela Superior de Guerra, Bogotá D. C., Colombia. Actualmente se encuentra vinculada laboralmente a la Superintendencia de Notariado y Registro. Correo electrónico: dianaplazass@hotmail.com 
deriva la alimentación de muchas familias en el territorio nacional, situación que se empeora a raíz del despojo de la tierra para el efecto y que según se ha reportado en varias oportunidades, va aparejada de la comisión de delitos de lesa humanidad como masacres perpetradas por grupos al margen de la ley, especialmente por paramilitares reportándose casos de graves violaciones a los derechos humanos por esas causas.

Palabras clave: seguridad alimentaria, biocombustibles, cultivos, pancoger, palma de aceite, víctimas y reparación.

\section{Abstract}

The present dissertation is devoted to establishing the relationship between big scale expansion of Palm Oil crops to produce biofuel in Colombia and regional food security. A detailed exposition of the environmental impact, land use, displacement of traditional crops and natural forest, land conflict and human rights, inclusion of biofuel production as a national government policy, to finally address the food security problem in Colombia. We expose arguments, after the review of previous studies in this subject, that despite the positive employment and energy effect of biofuels production, there is large negative consequences in the displacement of traditional agricultural production, and in the indirect increase in land conflicts including human right violations and violence related events. The large-scale Oil Palm production for biofuels have stripped away the main source of food of thousand in families in Colombia, which becomes a food security problem.

Keywords: security, food, production, sustainability, biofuels, crops, pancoger, oil palm, victims and repair.

\section{INTRODUCCIÓN}

La palma de aceite se ha constituido en un proyecto abanderado por grandes megaempresas bajo la premisa de que se busca generar la producción de biocombustibles e incrementar la generación de energía, siendo prima facie, un beneficio. Sin embargo, también se deben tener en cuenta los efectos económicos derivados de su siembra, especialmente por el cambio en la tenencia y uso del suelo en Colombia, así como 
las características sociales que se presentan, pues uno de los aspectos que se mencionan como amenaza causada por el cultivo de palma es la sustitución de cultivos de alimentos, para lo cual las condiciones geográficas y climáticas de algunos departamentos en Colombia, como Córdoba, Casanare, Meta y Guaviare, entre otros, son apropiadas para la siembra de los cultivos antes mencionados por el aumento de la demanda de biocombustibles y la búsqueda de sustitutos que hacen que la oferta actual sea insuficiente ${ }^{1}$.

Sin embargo, para la producción de biocombustibles es preciso alterar el medio ambiente casi que obligatoriamente, por cuanto para cultivar la palma africana se necesita una alta demanda de agua y para las épocas de sequía, se toma de corrientes superficiales y residuales, las cuales son devueltas contaminadas por los fertilizantes, abonos, pesticidas y fungicidas. Sería conveniente entonces, tener en cuenta qué efectos se producen en la fauna y la flora endémicas de las zonas apropiadas para el cultivo de la palma, así como cuáles problemas se generan en la salud de los seres humanos que se encuentran vecinos de las plantaciones.

Con base en lo anterior, se deduce que el Estado busca posicionar el cultivo de la palma africana con el objeto de producir aceite para alimentos y como biocombustibles. Este cultivo contribuiría a la generación de divisas, generaría empleo y ubicaría a Colombia como una de las economías emergentes más dinámicas y con posibilidades de emprender el despegue hacia un crecimiento autosostenido.

El Estado quiere enfocar el cultivo de palma, como un elemento esencial para obtener unos beneficios de carácter ambiental, porque el oxígeno liberado por los árboles compensaría con creces el $\mathrm{CO}^{2}$ producido por el biocombustible generado a partir del aceite vegetal para el tratamiento de aguas residuales.

1 Lo dispuesto en el párrafo esta en perfecta congruencia con la noción de política pública, para lo cual resulta procedente hacer referencia a lo dispuesto por Sandra Molina (2017), para quien: "El Estado busca en las políticas públicas un instrumento para tomar decisiones de modo racional sobre temas de gran envergadura. A diferencia de las leyes, en las políticas públicas confluyen varios elementos, varias temáticas y múltiples sectores interesados, y eso convierte la decisión en una decisión más compleja y difícil de tomar. En países latinoamericanos, las leyes son protagonistas en la fijación de límites a la sociedad, pero la política pública va más allá, establece un proceso de acción y decisión que se monitorea constantemente y que es flexible, a diferencia de la normatividad” (p. 82). 
De otra parte, se ha establecido que el cultivo de la palma está asociado con la generación y expansión del paramilitarismo en Colombia, por cuanto se ha comprobado la participación de estos grupos ilegales en las masacres que, por su magnitud, han sido denunciadas a los organismos de derechos humanos, como las de Mapiripán, San Carlos de Guaroa, Magdalena Medio y Urabá antioqueño, así como en los conflictos generados por los grandes latifundistas que con el respaldo o asocio de aquellos, se apropian de la tierra adjudicada por el mismo Estado al pequeño agricultor para el incentivo de los productos de "pancoger"

Desde el punto de vista ambiental, el cultivo de la palma de aceite altera los ecosistemas teniendo en cuenta que arrasa con los bosques, para dedicarlos a un monocultivo, afectando tanto la fauna como la flora nativas de algunas tierras que están dedicadas a la producción de alimentos, poniendo en peligro la seguridad alimentaria con los cultivos reorientados a la palma aceitera para la producción de biocombustibles.

La política agrícola del Estado colombiano en la última década, ha estado orientada de manera amplia a favorecer los cultivos de tardío rendimiento, creando unos estímulos directos otorgados a través de la Capitalización Rural (ICR) o exenciones tributarias como las establecidas en la Ley 818 de 2003 y el Decreto 1970 de 2005. Sin embargo, de acuerdo con el actual Plan Nacional de Desarrollo 2014-2018, se replantearon estos estímulos, por cuanto se estaban dejando en desventaja a los productores de pancoger.

Teniendo en cuenta lo anterior, el problema de investigación que se pretende desarrollar en el presente trabajo, se sintetiza en el siguiente interrogante: ¿Cuáles son los efectos del incremento y promoción de la utilización de la palma de aceite en la seguridad alimentaria del territorio colombiano?

Para lo anterior, se han de desarrollar los siguientes objetivos específicos: i) describir los antecedentes y la situación actual de la siembra de la palma de aceite en el territorio colombiano, ii) analizar las consecuencias del incremento de la utilización de la palma de aceite en territorios agrícolas y, iii) determinar los efectos y consecuencias en la seguridad alimentaria por la sustitución de cultivos agrícolas para la siembra de la palma de aceite.

2 Se denominan de "pancoger", los cultivos que proporcionan la alimentación de las familias que los cultivan. 


\section{MÉTodo}

Este trabajo de investigación es cualitativo, partiendo de las diferencias existentes entre la seguridad alimentaria y la utilización de terrenos fértiles para producción de biocombustibles. Además, busca demostrar cuáles son los factores que se deben tener en cuenta para contextualizar la sostenibilidad alimentaria frente a los cultivos de palma de aceite en el territorio colombiano.

Para el desarrollo de este trabajo, fue necesario hacer una revisión de textos escritos por la FAO, como sus revistas anuales sobre la seguridad alimentaria en el mundo, así mismo, las publicaciones hechas por las Naciones Unidas (ONU) y el Departamento de Agricultura de los Estados Unidos (USDA), desde el punto de vista internacional, y desde el punto de vista nacional, se tuvo en cuenta el Plan Nacional de Desarrollo (PND) 2014-2018, en cuanto a la evolución y apoyo a los cultivo de palma de aceite en el territorio nacional, respecto de los impuestos a los insumos para los cultivos, tanto de pancoger como de los de palma de aceite, entre otros.

De otra parte, se estudiaron los estándares de producción de los cultivos de palma de aceite para la elaboración de biocombustibles en experiencia comparada en América Latina, teniendo en cuenta los problemas de autoabastecimiento de su mercado interno, como en Chile, Costa Rica, Trinidad y Tobago y Venezuela, entre otros ${ }^{3}$.

\section{ESTUDIOS INVESTIGATIVOS SOBRE LAS CONSECUENCIAS DE LA SIEMBRA DE PALMA DE ACEITE EN Colombia}

En el presente acápite se pretenden referenciar los trabajos investigativos sobre la producción de biocombustibles a partir del incremento de la siembra de palma de aceite en Colombia, encontrando escritos en revistas ecológicas por medio de los cuales, autores como Tom Kucharz (2005), han hecho alusión a la problemática

$3 \mathrm{Al}$ respecto, Andrés Hurtado (2017) ha considerado que: "Desde finales del siglo xx el modelo clásico del derecho está viviendo un profundo agotamiento, debido a la insatisfacción de los modelos culturales y normativos. Esto ha traído como consecuencia el surgimiento de nuevas posturas antihegemónicas, que propenden hacia nuevas rutas que posibiliten la autonomía, la reconstrucción de la democracia, la redefinición de las funciones del Estado y el reconocimiento a otras formas de organización social por parte de nuevos actores emergentes" (p. 19). 
que dicha producción genera, enfocándose especialmente en el hecho de que se ha convertido en la justificación para el despojo de las tierras de quienes tienen una producción agrícola cerca de territorios donde se implanta la mencionada palma. En sus palabras, expresa:

Lo que existe detrás de la palma y su relación con la contrarreforma agraria, desarrollada en una nueva fase a través del proceso de "desmovilización parainstitucional", como dice un informe de Justicia y Paz, es la "experimentación cualificada" de un laboratorio de guerra, terror e impunidad y un modelo de represión y de degradación ambiental que se puede extender por toda América Latina.

Ese ha sido el análisis que otros autores han efectuado a través de trabajos de grado, encontrándose el desarrollado por Camilo Rey Sabogal y denominado: "Análisis espacial de la correlación entre cultivo de palma de aceite y desplazamiento forzado en Colombia”, donde encontró que existe una correlación entre la siembra de palma de aceite y el desplazamiento en algunas unidades geográficas del territorio nacional, teniéndose como conclusión que donde se impulsó su producción, fue donde mayor desplazamiento se generó en las últimas décadas (2013).

La suscrita quiere dar a conocer con su investigación, que la adquisición de la tierra fértil para el cultivo de productos que garanticen la seguridad alimentaria o denominados de pancoger, está siendo utilizada de manera indiscriminada en algunas regiones en Colombia para cultivos de palma africana por multinacionales a las que no les interesa la conservación, cuidado y mantenimiento de la tierra, el ecosistema, la flora y la fauna que en ella existen, sino que por el contrario, solo tienen interés por los cultivos ocasionales que una vez cumplan con su ciclo de producción, jamás esta tierra podrá ser reutilizada para ninguna otra clase de siembra, ya que pasado el tiempo de producción, esta queda totalmente infértil, aunque una pequeña proporción sea utilizada para ganadería. El daño ecológico para la región en donde se cultive la palma africana es tan grande que aumenta la producción de $\mathrm{CO}^{2}$.

Además de los trabajos precedentes, se tiene el estudio denominado: "Agroindustria y conflicto armado: el caso de la palma de aceite”, el que deja entrever que: 
[...] a partir de denuncias sobre problemas de tierras en las zonas palmeras ubicadas alrededor del mundo, se creó la Mesa Redonda de Aceite de Palma Sostenible (RSPO), y, a su vez, algunos casos en donde en Colombia se ha asociado al cultivo, por un lado, con el desplazamiento forzado y, por el otro, con la prevención del conflicto" (Ocampo Valencia, 2009).

Ya en lo que tiene que ver con la afectación a la seguridad alimentaria, se pueden encontrar aportes del Observatorio de Economía Latinoamericana, que publicó el trabajo titulado: "Palma aceitera y la seguridad alimentaria en María La Baja, Montes de María. 2000-2008”, del que se extracta que las siembras de palma de aceite han desplazado a los cultivos que proporcionan la seguridad alimentaria, afectando especialmente a la población de escasos recursos que no se vincula a la producción de esta, lo que conlleva a su vez a que los alimentos para su comida, tengan que ser trasladados desde otros municipios. Además, el problema no se concreta solamente en ese supuesto fáctico, sino en que muchas personas tendrán que buscar adherirse a la producción de la palma de aceite. Ello se precisa en el estudio mencionado, así:

\footnotetext{
Por otro lado, la diferencial de los salarios reales, impulsará con mayor fuerza a los campesinos del municipio a vincularse al cultivo de palma, abandonando los otros cultivos, tan rápido como se incremente el salario real en la palma. Este incremento del salario real se dará, cuando el cultivo incorpore mayor tecnología en su proceso de producción y se ajusten los eslabones de la cadena productiva. Los entrevistados, reconocen que existe hambre en María La Baja, y esta situación se incrementará en la medida en que disminuyan las aéreas sembradas de cultivos como la yuca, el plátano, el arroz y el maíz amarillo, base de la alimentación de los pobladores (Menco Rivera, 2011).
}

Cómo podemos observar, cualquier economía por sólida que sea, se verá afectada y más aún cuando la tierra para cultivar no pueda dar el fruto que se espera, ya que esta va perdiendo fertilidad lo que conllevará a la expansión o traslado de los cultivos de palma de aceite a otras regiones del país, pudiendo llegar al límite del desplazamiento en general de los cultivos de pancoger, dejando en grave peligro la seguridad alimentaria en nuestro país.

Se hace necesario entonces, crear políticas serias de apoyo a los agricultores, no solo en dar la tierra al campesino pobre como lo estipula o enmarca la Ley 190 de 1994, 
sino que también se disminuyan o regulen los impuestos a los insumos agrícolas, para evitar un desabastecimiento y tener que comprar a otros países los productos básicos para la alimentación de nuestra población, como es el caso de El Salvador y Venezuela, entre otros ${ }^{4}$.

\section{Contextualización geográfica, mapas o gráficas}

En la Figura 1 se presenta un mapa que permitirá determinar el incremento del cultivo de palma de aceite en Colombia entre 1998 y 2015 (Proyecto Planeta Paz, 2012).

Los mapas nos permiten ver o confrontar la realidad frente a la publicidad del Gobierno, y las consecuencias de la falta de apoyo de un Estado a su población, para el desarrollo del mismo, dándole participación general a la misma población y no el favorecimiento a una parte de ella. Se deben elevar los niveles de productividad para crear un ambiente más beneficioso a la inversión e introducir cambios estructurales con una política efectiva de mejoramiento en el gasto público, para la creación de nuevos activos que produzcan crecimiento agrícola.

4 Al respecto, se coincide con Julián Osorio (2017) para quien: "La contextualización de la función social del derecho en la construcción de una cultura de paz en la vivencia del posacuerdo está mediada por la eficacia social de la gestión del conocimiento jurídico para profundizar la modernidad social, como formación de ciudadanía y sujetos de derechos; la democracia participativa, como deliberación pública en derecho, y la democratización de las prácticas económicas, con sentido de la sostenibilidad ambiental, como negociación de intereses en conflicto siguiendo procedimientos en derecho" (p. 120). 


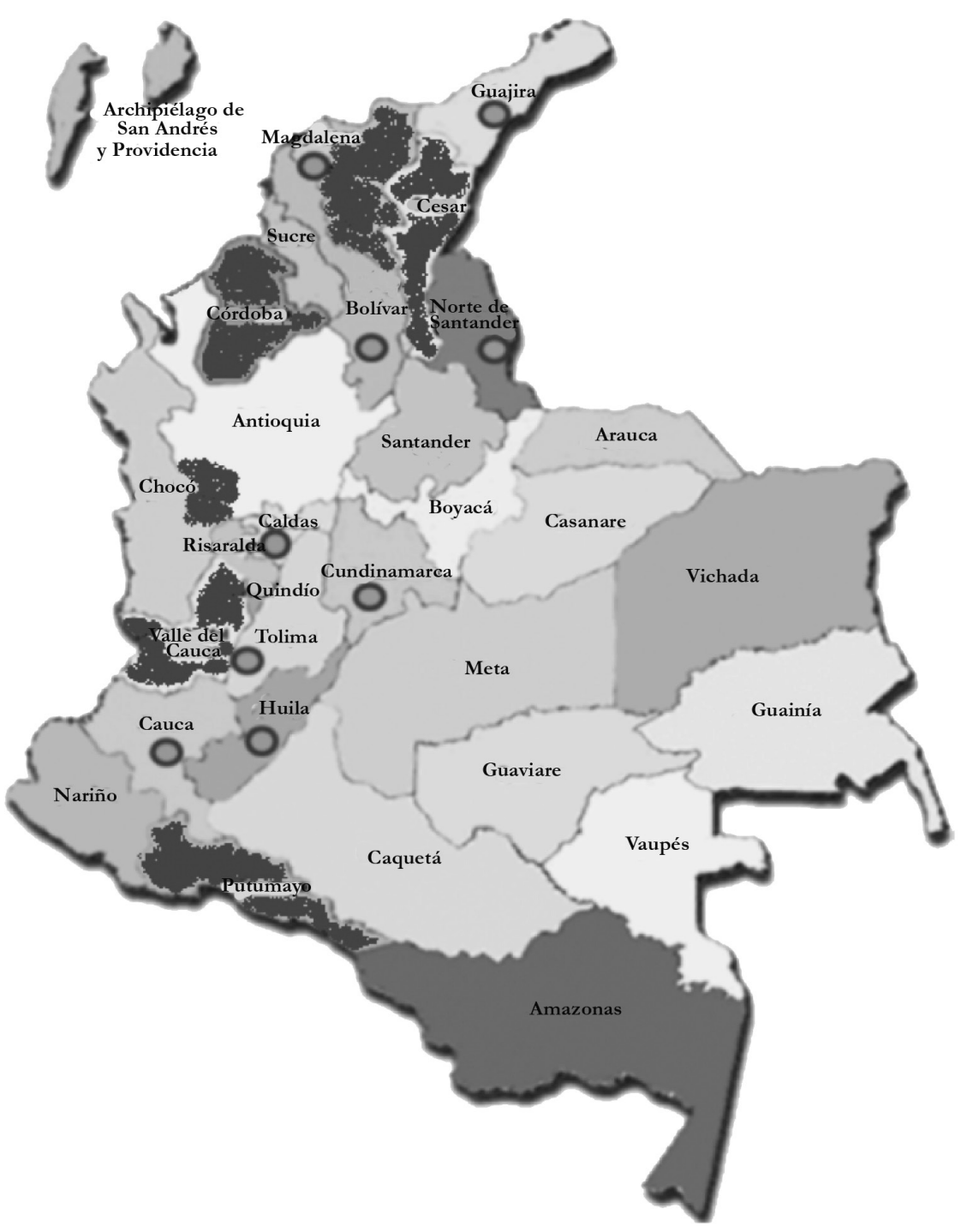

Figura 1. Incremento del cultivo de palma de aceite en Colombia entre 1998 y 2015

Fuente: Proyecto Planeta Paz, 2012. 


\section{ANTECEDENTES SOBRE El USO DEL SUELO EN COLOMBIA}

El principal bien generador de riqueza de un Estado y esencialmente del colombiano, es la tierra y la disputa por la apropiación de esta y del suelo. Dicha situación se remonta incluso al año 1910, donde se explica el quererse apropiar de una u otra forma de ella, por ser un bien que se puede vincular al prestigio social y el poder político de las élites y de los poseedores de grandes extensiones de tierra. Aún ahora sigue siendo un bien de valorización como una reivindicación histórica del campesinado.

Este modelo fundamentado en la gran propiedad y los procesos de apropiación de la tierra por terratenientes, comerciantes, militares, políticos y personas al margen de la ley como los grupos armados independientes durante la era republicana, crearon una estructura agraria, desigual, conflictiva, concentrada y polarizada, que no ha ayudado a generar unas mejores condiciones para la evolución, desarrollo y articulación de la agricultura en Colombia, ni una política de tierras, tendientes a mejorar las condiciones de vida de la población rural. La elevada concentración de la propiedad rural en Colombia, ha contribuido con sus políticas a ese proceso, de manera notoria durante la era republicana en el siglo xIX, y hasta nuestros días, pese a los intentos de recuperar las tierras del Estado como los baldíos, y posteriormente con la redistribución de la propiedad a través de la reforma agraria. El Estado ha invertido cuantiosos recursos en programas y proyectos de desarrollo rural, que no han generado un impacto positivo en la estructura de la propiedad, ni han modificado las condiciones estructurales en que se desenvuelve la vida rural (Machado y Vivas, 2009).

El impacto negativo de las malas políticas de desarrollo rural que ha implementado el Estado colombiano en las cuatro últimas décadas, en el que traslada la pobreza del campo a la ciudad, y a esta problemática le sumamos, la incursión de los grupos armados y el narcotráfico entre otros, ha obligado a la población rural en general a un desplazamiento forzado, describiéndose dicha situación así:

La apropiación de la tierra durante las últimas décadas con fines políticos y militares y paramilitares, ha seguido un patrón tradicional para acumular propiedad y generar rentas institucionales, con la vía de la valorización y sin el pago de impuestos, generando un retroceso en los derechos de propiedad y en las relaciones sociales en el campo, como en muchas regiones del país (Machado y Vivas, 2009). 
La situación no es clara, porque no se ha presentado un estudio serio y sistemático de la distribución de la propiedad rural y su apropiación irregular y que es necesario dilucidar para buscar soluciones adecuadas, en términos de políticas públicas. A la evolución de la problemática de la propiedad rural en Colombia, no se le ha hecho un seguimiento serio en cuanto a la historia y modo de adquisición de la propiedad rural y al poder político de la sociedad colombiana, que recae directamente en la política de tierras y en la evolución del problema agrario.

En Colombia, hasta la década de los sesenta, no había existido ninguna política sobre tierras que siquiera tratara de resolver los problemas de la población campesina, así como tampoco una política económica para este sector, pero sí han existido políticas para beneficiar a algunos grupos que se podrían denominar privilegiados, lo que ha conllevado a que se presenten diferentes conflictos respecto a la tenencia de la propiedad en el sector rural 5 .

\section{El surgimiento de otras economías y el desplazamiento de los cultivos. El caucho}

Hacía el siglo XIX, se empiezan a implementar nuevas formas de economía motivadas por el auge de crecimiento y nuevos modos de empleo, así pues, surgen algunas compañías dedicadas a la producción del caucho, como lo es la denominada "Calderón", que se estableció en el departamento del Putumayo, generándose hacía el siglo Xx la competencia por el desarrollo de economías extractivas entre Brasil y Colombia, para poder fortalecer la explotación del caucho en Colombia, lo que produjo la colonización de la población indígena de ese territorio, adjudicándose tal hecho al terrateniente peruano Julio César Arana, lo que hace sin la ayuda del Gobierno nacional

5 Atendiendo lo dispuesto, se considera que: "Cada vez se torna más necesario actualizar el Código Civil colombiano, el cual en 2017 cumplió con 130 años de existencia. Las reformas y contextualizaciones que se le han hecho a la normativa son coyunturales, parciales y desarticuladas frente a las realidades sociales e institucionales del país, que por cierto ha tenido profundas transformaciones en este lapso. Ni hablar que urge una integración del derecho civil con el derecho comercial, como recientemente han realizado de manera ejemplarizante países como Argentina. Dentro de este contexto, los derechos civiles sobre las obligaciones y las personas requieren una creatividad y amplitud analítica por parte de la academia para suplir estas carencias dentro del proceso de aprendizaje del derecho tanto en los niveles de formación profesional como posgradual” (Cadena, 2018, p. 260). 
y aun cuando pudo generar exportaciones a otros países, su decadencia llegó por el reproche a la esclavitud que se veía en sus latifundios (Reyes, 1990).

Con el inicio y posterior culminación de la Segunda Guerra Mundial entre los años 1939 y 1945, Alemania tomó la iniciativa en desarrollar productos sintéticos con propiedades similares al látex, el cual acabaría con los sueños de las grandes casas exportadoras del caucho natural a nivel mundial. El impacto internacional incidió en que el Estado colombiano se concientizara de los hechos ocurridos en el Putumayo con los pueblos indígenas ya que desconocía la riqueza de su tierra en la producción del caucho negro.

La industria del caucho en Colombia comenzó su auge en los años cincuenta, con algunas empresas importantes como Croydon y Grulla entra otras, para la producción de calzado, elementos deportivos y otros artículos en general, ampliándose posteriormente el mercado en la producción de llantas y neumáticos con empresas como Goodyear, entre otras.

\section{Las bananeras y las colonias}

En 1928 se presentó uno de los pasajes más tristes de la historia colombiana, la "Masacre de Las Bananeras", un hecho que marcó al Estado colombiano, no solo porque transcurridos 25 ańos desde la pérdida de Panamá, por la "venta del territorio" a Estados Unidos, sino por la compra de tierras por empresas extranjeras como la United Fruit Company, en la que el obrero no contaba con un respaldo laboral, el que estaba en contra de su dignidad humana, sino que hace que la mujer comience con su vida laboral, ya que en la época tenían ellas otras ocupaciones, pero con la llegada de alguna multinacionales empezaron a hacer parte de la nómina, desarrollando la labor de recolección de pińa y plátano (Galeano, 1997).

El 5 de diciembre de 1928 los trabajadores de la United entraron en huelga dejando de lado la recolección en las plantaciones del Magdalena, exigiendo una vivienda digna, buen pago y servicio médico, pero un representante del Gobierno nacional quiso colaborar con la multinacional bananera United con el cese de la huelga, citando a gran parte de la población en la plaza del municipio de Ciénaga, los cuales fueron rodeados por gran cantidad de hombres armados quienes dispararon en tres 
ocasiones a la población, que se había congregado allí con el engaño de que se iba a firmar la negociación. El vocero del pueblo Jorge Eliecer Gaitán defendió a más de 5000 obreros demostrando su inocencia y cómo la Unitedf Fuit Company cometió la masacre que marcó la postura sobre el monopolio del Estado (Elias Caro, 2011).

La zona bananera enmarcada en la masacre, situada entre Santa Marta, Ciénega, Aracataca y Fundación, fue producto del ataque más cruento de la historia, originado por la codicia y la ambición de apropiarse de la tierra, ante el reclamo de derechos fundamentales, necesarios para la existencia del hombre en condiciones dignas y su desarrollo.

Esta "invasión” producida por grandes empresas multinacionales que querían explotar la tierra sin tener en cuenta el dańo social, cultural, agrícola y el bienestar de los habitantes del territorio nacional, no solo se generó por un gran descuido por parte del Gobierno colombiano, sino que permitió la apropiación indebida de la tierra, tanto así que creó la figura de la posesión sobre el título de propiedad, por encima de la explotación de la tierra propia de nuestros campesinos, que venían explotándola de generación en generación.

Una de las consecuencias de la Masacre de las Bananeras, fue el retiro de la United Fruit Company, pero los terratenientes y políticos de la región, no solo se apropiaron de las tierras, sino que hasta la fecha no ha mejorado en nada el bienestar de los trabajadores en ninguna de las propuestas hechas por los obreros en 1928 en la huelga de las bananeras.

\section{Primera regulación del uso de la tierra}

Para poder entender el valor, el uso y la distribución de la tierra en Colombia, es indispensable conocer la normatividad que la rige, partiendo de la "Ley Tocaima" o Ley 137 de 1959, la cual se originó con el fin de fortalecer el desarrollo de los municipios y contribuir con el saneamiento de la propiedad del inmueble, promulgándose unas normas sobre los ejidos, como la Ley 41 de 1948 y la Ley 160 de 1994, en la que se estableció el concepto de UAF, Unidad Agrícola Familiar, conocida como la empresa básica de producción agrícola, cuya extensión la establece el Gobierno por medio de la Resolución 041 de 1994, por zonas en las que le permite a cada una de 
las familias una remuneración por su trabajo y disponer de un excedente capitalizable que coadyuve a la formación de su patrimonio. La UAF no requerirá normalmente para ser explotada sino del trabajo del propietario y su familia, sin perjuicio del empleo de mano.

La Ley 160 de 1994 regula la adjudicación de baldíos en Colombia con el objeto de promover y consolidar la paz, a través de mecanismos encaminados a conseguir la justicia social y el bienestar para la población rural y prevenir la concentración de la propiedad, además de regular la ocupación y aprovechamiento de las tierras baldías de la nación, dando preferencia en su adjudicación a los campesinos de escasos recursos por una sola vez y para ello reglamentó la distribución de los baldíos por medio de la Resolución 041 de 1994, para determinar la unidad agrícola familiar y los mecanismos de evaluación, revisión y ajustes periódicos cuando se presenten cambios significativos en las condiciones de la explotación agropecuaria que la afecten y evitar la acumulación y división de la tierra adjudicada.

Fijará en salarios mínimos mensuales legales el valor máximo total de la UAF que se podrá adquirir mediante las disposiciones de esta ley. Para determinar el valor del subsidio que podrá otorgarse, se establecerá en el nivel predial el tamaño de la unidad agrícola familiar (Ley 160, 5 de agosto de 1994).

\section{Irrupción de la agroindustria en Colombia}

La producción de palma de aceite en Colombia se expandió específicamente entre los años 1998 y 2004, de lo que da cuenta Fedepalma quien se ha encargado de desplegar actividades sobre el desarrollo de este sector, generando ofertas comerciales a favor de quienes se dedican a la explotación y comercialización de este cultivo, pero el cual se ha asentado en favor de los terratenientes. Misma situación que acontecía con los azucareros sobre quienes se dice:

[...] para responder a esta cuestión es necesario señalar que algunos estudiosos mostraron el ascenso del ingenio y la producción de azúcar en general como un proceso lineal y simple, guiado por una oligarquía terrateniente de ingenios azucareros. Tendencia que, de manera contradictoria, se ensambla, por otra vía, con las hipótesis. Quienes caracterizaron la producción agrícola en las áreas rurales, con excepción del café, y los em- 
presarios del agro como fuente innata de trabas estructurales para el progreso del país; creando un futuro para esta agroindustria (Sánchez Mejía y Santos Delgado, 2014).

Ahora bien, debe tenerse en cuenta que la escala de ascenso de los mercados, la globalización ${ }^{6}$ y la internacionalización de las economías, ha impulsado el auge de aceites y grasas lo que se coadyuva con el posicionamiento del aceite de palma como el principal aceite vegetal producido y comercializado en el mundo, situación que ha sido criticada por ambientalistas pues, si bien es una alternativa para la contaminación causada por los combustibles fósiles, lo cierto es que su efecto repercute negativamente en la misma fauna y flora, la que se devasta o acaba para darle prelación a este cultivo, producción que en definitiva va en aumento. Al respecto, se puede contextualizar lo dicho de la siguiente manera:

El sector palmero a través de Fedepalma buscó por parte del Gobierno nacional a mediados de 2007, del documento Compes, políticas para el desarrollo competitivo del sector palmero colombiano, el cual se constituye en una guía importante de las acciones que desde los sectores público y privado se deberán impulsar y comprende actualmente varios programas en las áreas de economía y estadística, comercialización, desarrollo sostenible, capacitación y desarrollo empresarial, y tecnología agroindustrial. A través del programa de economía y estadística se despliega el análisis y gestión de políticas económicas y sectoriales; el monitoreo de los costos de producción y de la competitividad sectorial; y el desarrollo de un sistema de información y estadísticas del sector palmero (Fedepalma, 2007).

Así, a través de un programa de capacitación y desarrollo empresarial, se buscó elevar la calificación del recurso humano vinculado a las diversas actividades de la agroindustria, con la finalidad de promover la empresarización de los pequeños palmeros, incluyendo algunos tratados como el convenio interinstitucional con el Sena, que se ha diseńado para un adecuado escenario de competencias que se incrementaría con un trabajo de la Mesa Sectorial sobre la Palma de Aceite (Fedepalma, 2007).

6 De conformidad con Blanco (2017), es importante resaltar que: "El modo de inserción de gran parte de los países de América Latina, y particularmente los andinos, en la globalización ha sido precario, incierto y frágil. Entidades locales que podrían aparecer momentáneamente como ganadoras por contar con ventajas vinculadas a mercados, precios o infraestructura, no tienen un estatuto consolidado y, como consecuencia de ello, pueden rápidamente desplomarse en las cadenas de producción o circulación transnacional” (p. 67). 


\section{LA IMPORTANCIA DEL BIOCOMBUSTIBLE Y LA UTILIZACIÓN DE LA PALMA DE ACEITE EN LOS PLANES DE DESARROLLO}

Es relevante indicar que, en el Plan Nacional de Desarrollo, los biocombustibles se consideran como bienes de alta generación de valor, que pueden ayudar a la producción agropecuaria en Colombia; y la producción del aceite de palma y caña de azúcar, se han constituido en insumos esenciales en el proceso productivo del biodiesel y el etanol, respectivamente. La política nacional de biocombustibles en Colombia ha adoptado medidas en una mezcla que contenga un $10 \%$ del alcohol carburante y un $5 \%$ de biodiesel para ACPM.

De acuerdo con la Ley 939 de 2004, se han creado estímulos tributarios para el cultivo de aceite de palma en cuyo caso han generado exenciones tributarias por 10 años para el desarrollo de nuevas plantaciones del mencionado producto que hubieren sido debidamente registradas ante el Ministerio de Agricultura, evaluándose el impacto que tiene el uso alternativo de la palma de aceite en la generación de biocombustibles, lo que colateralmente ocasiona el incremento en la demanda de los mismos y por tanto en la política nacional de biocombustibles, lo que a su turno repercute en los precios de productos agrícolas y otros derivados. Y es que la mencionada política surge de la siguiente postura:

\footnotetext{
Existen evidencias que apuntan hacia una crisis energética de los combustibles fósiles a nivel mundial, fundamentadas en el creciente consumo por habitante y en el aumento de la motorización por región, el crecimiento de la demanda en las economías emergentes que supera la dinámica de la actividad de producción según un estudio adelantado por Bolívar, Mostany y García (2006), y que aunado a la disminución creciente de las reservas de petróleo, generan incertidumbre sobre el panorama a futuro (Cortés, Moreno, Albornoz y Poveda, 2011).
}

Por ello a nivel mundial y a través de algunas organizaciones, como la Comisión Mundial de Energía, se han impulsado proyectos que propenden por la sustitución de fuentes de energía no renovable por aquellos recursos que sí lo son, especialmente para los mencionados biocombustibles. 


\section{LOS EFECTOS NEGATIVOS DEL CULTIVO DE LA PALMA DE ACEITE El paramilitarismo frente al latifundio}

Durante muchos años, la propiedad de la tierra ha sido la generadora de grandes disputas en el seno de la sociedad, pero también de conflictos suscitados por grupos ilegales que han generado una grave crisis humanitaria en el territorio colombiano, especialmente por grupos paramilitares que han coadyuvado al destierro de miles de familias a través de la perpetración de masacres que generan una grave crisis humanitaria y la violación sistemática de derechos humanos dentro del país. Lo anterior ha llevado al incumplimiento de las obligaciones internacionales que ha adquirido Colombia en el marco del Sistema Universal de Protección de los Derechos Humanos, esto es, en la Organización de Naciones Unidas, como en el Sistema Interamericano de Derechos Humanos, este último - a través de la Comisión Interamericana de Derechos Humanos y de la Corte Interamericana de Derechos Humanos-, ha llamado la atención por el quebrantamiento de las libertades y prerrogativas establecidas para las personas en la Convención Americana de Derechos Humanos (CADH).

Así pues, el cultivo de la palma de aceite no ha sido ajeno a la irrupción de movimientos paramilitares con el fin de desplazar a los agricultores y poder incrementar el cultivo de este insumo. Los casos se han presentado, por ejemplo, en el departamento del Cesar, donde las comunidades de Terraplén una vez que recuperaron los playones comunales y la ciénaga, "fueron desplazadas por el paramilitar Alirio Díaz, con el objeto de acabar con la ciénaga y sembrar palma aceitera (Comisión de Interlocución del Sur de Bolívar, Centro y Sur del Cesar, CISBCS, 2015). Dicho desplazamiento obligó a la comunidad a buscar otras tierras, sin que sobre el particular hubiera reparo alguno, pues otros paramilitares inclusive delimitaron la zona a través de mallas, sin que hubiera un pronunciamiento por parte de las autoridades. Se llega a describir dicha problemática así:

Las comunidades presentaron las denuncias en reiteradas ocasiones frente al daño ambiental, la construcción de murallas, el taponamiento de entrada y salida de cańos, quema y tala de bosques, la apropiación de los playones y las amenazas a su integridad física por parte del señor Alirio Díaz, a pesar de esto, algunos campesinos que han querido trabajar la tierra para el sustento familiar, fueron desalojados por personas

VIeI / Vol. 13, n. ${ }^{\circ} 2$ / Julio-diciembre 2018 / Bogotá D. C., Colombia / Universidad Santo Tomás / Pp. 183-220 
armadas, quemándoles sus chozas y destruyéndoles sus cultivos de pancoger (Comisión de Interlocución del Sur de Bolívar, Centro y Sur del Cesar, CISBCS, 2015).

De hecho, se reseńa que a través de las Resoluciones No 317, 321 y 325 de 2011, el Incoder trató de solucionar los problemas con el deslinde y realineamiento del municipio de San Martín en Cesar; medidas que resultaron insignificantes ante las amenazas, las que se hicieron extensivas incluso a funcionarios estatales, lo que se tradujo en una intervención ineficiente pues los grupos al margen de la ley seguían con la posesión irregular de la tierra, lo que se referencia en la Figura 2 del presente escrito. Se ratifica que las soluciones por parte de las autoridades públicas no han sido las mejores para atender las reclamaciones de la comunidad, pese a que se trata de un caso con grandes repercusiones y que requiere acciones urgentes.

Las Naciones Unidas se han pronunciado también respecto de esa situación en zonas como el Chocó, donde el desplazamiento es uno de los problemas más grandes generados por la producción de la palma africana, identificándose los siguientes inconvenientes:

\footnotetext{
Tres mecanismos concretos configuran este desplazamiento; de una parte, la renovación de cultivos y el robustecimiento del proceso de extracción en manos de las grandes empresas; de otra, la consolidación de la producción de fruto en manos de los palmeros independientes a través de nuevas áreas sembradas; y finalmente, la descompactación de la fuerza laboral a través de la conformación de empresas asociativas de trabajo con las cuales se contratan diferentes tareas del proceso productivo (ACNUR, 2004).
}

De hecho, la ACNUR relata en su informe que las grandes empresas han adoptado métodos ilegales para la conservación y expansión de la palma de aceite, lo que se coadyuva por el establecimiento de grupos paramilitares, hablándose de grandes omisiones por parte de las autoridades estatales, considerándose que: "[...] Estas omisiones podrían calificarse de violación de derechos humanos, cuando el Estado haya dejado desprotegidos a sus ciudadanos y consecuentemente haya permitido que algunos de sus derechos sean dañados" (ACNUR, 2004).

En palabras de esta organización: 


\begin{abstract}
En algunos casos, cuando se ha hablado de una participación directa de movimientos paramilitares en la implementación de los cultivos y se ha podido observar una connivencia directa o indirecta entre organismos del Estado y tales grupos, la violación de los derechos de propiedad, laborales, vida o integridad física sería directa. Como se ha visto a nivel mundial en el capítulo 1, la implementación de cultivos a gran escala ha significado violaciones al derecho a la vida y a la integridad física, a los derechos laborales, a la propiedad, a los derechos culturales y ha causado desarraigo y desplazamientos.
\end{abstract}

\title{
Situación aCtual de la TIERRA y los alimentos EN Colombia
}

Cómo se manifestó en el tema anterior, quienes poseen la tierra fértil que estaba en manos de los campesinos para cultivar productos de pancoger, son terratenientes que no solamente tienen el respaldo de las autoridades municipales y departamentales, sino que también trataron de incluir en el plan de desarrollo 10 años más para proteger e incentivar el cultivo de la palma de aceite.

Para la producción de biocombustibles, situación que se dio entre los años 2004 y 2014, algunos senadores que se dieron a la tarea de estudiar cuidadosamente el plan de desarrollo, notaron que este beneficio se iba a ampliar por 10 años más a los terratenientes, los cuales tendrían nuevamente el bajo costo de los insumos para sus cultivos; mientras que para los cultivos de pancoger, los insumos no tenían ni la más remota posibilidad de que bajaran, para que los campesinos pudieran seguir cultivando sus alimentos, siendo que es responsabilidad del Estado proporcionar a sus habitantes el mínimo vital.

El aumento de las tierras de monocultivos, "sigue siendo la causa principal del crecimiento de los campesinos con pocas posibilidades de cultivar sus productos, como es el caso de los arroceros en Colombia" (Salcedo y Guzmán, 2014) que llegaron a ser, junto con los cafeteros y azucareros, la base de la agricultura en nuestro país, y ahora este producto tiene que ser importado, porque los insumos aumentaron considerablemente su costo y no existen subsidios por parte del Estado para que sigan sembrando arroz; por este motivo, 
[...] los cultivadores de arroz han tenido que vender a los terratenientes su tierra a bajo costo por presión sobre los recursos agrícolas, se tendrá que aumentar constantemente la productividad con respecto al nivel relativamente bajo que se observa actualmente. Para ello, se deberá hallar una solución eficaz a las principales limitaciones que impiden el aumento de la productividad, como la falta de incentivos favorables, las limitadas inversiones públicas y el deficiente apoyo institucional (Sánchez Mejía y Santos Delgado, 2014).

Se ha referenciado conforme a las experiencias nacionales, que el aumento de la producción se asocia a una reforma o cambio en las condiciones de la sociedad, llegando a un período de receso que conlleva a los agricultores a situaciones complejas, debiendo alejarse de sus tierras y cultivos, de los cuales derivan su sustento.

El cultivo de palma de aceite ha venido creciendo considerablemente, en cabeza de unos pocos terratenientes, como Aceites Manuelita, que además de tener los cultivos de caña de azúcar, se ha venido tomando regiones en el Valle del Cauca, Meta, (San Martín, San Carlos de Guaroa, entre otros) Chocó, Casanare, Putumayo y en sur del país, patrocinando a algunos pequeños agricultores por 5 años, mientras empiezan a dar frutos las primeras palmas de aceite, que tienen una vida útil de 25 y así producir insumos para la producción de biocombustibles (ACNUR, 2004).

Es de suponer que la mayor parte de las inversiones necesarias procedan del sector privado, y que tales inversiones dependan fundamentalmente de la existencia de un ambiente propicio en los contextos nacional e internacional.

El consumo interno de productos alimentarios representa un porcentaje considerable y cada vez mayor de la producción.

Haciendo historia en el país, en la década de los sesenta, Colombia no era importadora de arroz, pero ya para la década de los noventa, se importaban 3.5 millones de toneladas, cifra que se preveía hasta el 2013, y que aumentaría a más de 7.5 millones de toneladas para el 2015. Situación que cambió radicalmente, ya que el Estado colombiano decidió acudir a la importación teniendo en cuenta el TLC, dejando a la producción interna, desprotegida para los grandes y pequeños cultivadores; según las proyecciones, se alcanzarían más o menos 15 millones de toneladas en el 2015 (FAO, 2013). 


\begin{abstract}
La evolución de la producción, el consumo y el comercio demuestra ampliamente la creciente dependencia de las importaciones de alimentos. Los pronósticos de la FAO para 2015 indican que esta dependencia seguirá creciendo. En el caso en que no sea posible asegurar las importaciones comerciales necesarias o que la ayuda alimentaria no pueda compensar el déficit, el consumo alimentario per cápita disminuirá inevitablemente (FAO, 2013).
\end{abstract}

\title{
Producción actual de los alimentos en Colombia
}

Ahora bien, siguiendo a López Hernández (2012), la producción de alimentos en Colombia, es generada por productores rurales (campesinos e indígenas y empresarios y obreros agrícolas), quienes deben producir los alimentos no solo para procurarse su propia alimentación, sino también para cubrir para el mercado interno, con lo cual proporcionan estos para los habitantes urbanos y aquellos pobladores rurales que no trabajan en labores agropecuarias, y simultáneamente, obtienen ingresos, acceden a otros bienes y servicios producidos por el resto de la economía.

En un contexto mundial, en donde la producción y comercialización de alimentos básicos es subsidiada en los países desarrollados, la importación de estos bienes, abaratados en contra de las disposiciones del libre comercio, se hace atractiva en los países en desarrollo como Colombia; la política agropecuaria, buscando competitividad, estaría fomentando esta producción tropical exportable como respuesta a la imposibilidad de hacer frente, efectivamente, en el esquema actual de comercio internacional, a la importación de alimentos altamente subsidiados (López Hernández, 2012).

Como consecuencia de lo anterior, el suministro de alimentos básicos para el país está siendo garantizado con una participación cada vez mayor de las importaciones de estos bienes. Esta situación queda demostrada en alimentos básicos como el arroz, el maíz, el trigo, la cebada y el plátano, cuyas importaciones han crecido considerablemente en los últimos años, afectando la autosuficiencia en la producción y generando una situación de dependencia externa en el suministro de los mismos.

El anterior panorama, trae consecuencias para los agricultores y sus fuentes alimenticias, puesto que algunos alimentos básicos en el país se han venido suministrando a través de importaciones, lo que repercute negativamente en la producción nacional, pues 
todo depende de alguna manera de lo que se pueda traer del exterior, a lo cual se sumó el tratado de libre comercio con los Estados Unidos (TLC) del que se puede indicar:

El impacto del TLC en el sector agrícola colombiano, no solo pasa por la ayuda del gobierno norteamericano a sus productores del sector primario, sino a las trabas administrativas para la exportación de nuestros productos. Entre estos obstáculos están las medidas y controles fitosanitarios, que hacen que gran parte de la producción exportable agrícola de nuestro país no traspase las fronteras (Delgado Munévar, 2004).

Bien es sabido que este tratado generó un gran impacto en la economía colombiana, del que no se liberó la agricultura, lo cual llevó a límites que algunos califican como extremos, conllevando a situaciones de pobreza, desempleo y especialmente, para efectos del presente trabajo, en la concentración mayor de la tierra, además de la disminución o desaparición de los cultivos de cereales y oleaginosas que no puede olvidarse, abastecen los mercados internos. Se ha relatado sobre ese particular:

Colombia vislumbra problemas en sectores como el algodón; el arroz; cereales; el maíz, la fibra de algodón, la soya, la caña y la remolacha de azúcar, la leche fresca, la carne de pollo, la carne de cerdo y la carne de res entre otras, debido a los bajos niveles de productividad en estos sectores y a las altas ayudas del Gobierno de los Estados Unidos. En este aspecto uno de los temas de mayor trascendencia es la denominada producción transgénica, dado el desarrollo que se tiene en los Estados Unidos sobre la manipulación genética de los productos agrícolas y sus altos niveles de productividad. La relación costo-beneficio del TLC para el sector agropecuario colombiano es negativa y ello tendrá repercusiones en el resto de la sociedad colombiana en términos de estabilidad social y bienestar general, incluyendo los efectos en materia de dependencia alimentaria al abandonar el cultivo de los productos que componen la dieta básica de la población y especializarse en productos tropicales (Grueso, 2014).

\section{IMPACTOS LABORALES, SOCIALES Y EN EL ESTILO DE VIDA}

Debe indicarse que la agroindustria de la palma de aceite es poco menos intensa que la mano de obra que se utiliza en la producción de otros cultivos y su impacto en la generación de empleo no es tan eficiente, pues generalmente estos cultivos se ubican en regiones de baja densidad demográfica. Ahora bien, desde el punto de vista social, 
las comunidades que pertenecen al gremio, por obvias razones se han beneficiado de trabajos, manteniendo mejores escalas de ascensos que otros agricultores, especialmente en departamentos como el Meta y en localidades como Acacías, Barranca de Upía, Castilla La Nueva o Cumaral, y es que algunas federaciones como Fedepalma, han asegurado que están en condiciones de generar empleo para toda la población de esos territorios que sea económicamente activa y además para pobladores de otras municipalidades.

En el ámbito de la calidad de vida de quienes se encuentran cerca a los cultivos de la palma de aceite, se pueden identificar patrones de estilo, esencialmente por la carencia de recursos económicos que se aumentan por factores como viviendas inadecuadas, que no cuentan con la prestación de servicios públicos domiciliarios, en fin, un hacinamiento crítico.

Si bien es cierto, la agroindustria de la palma de aceite aparentemente no es tan intensiva en mano de obra como otros cultivos, sin embargo, y comparando los municipios que cultivan la palma con los que cultivan los productos de pancoger, se puede ver el impacto en la generación de empleo teniendo en cuenta las condiciones de vida de cada departamento. La palma de aceite remunera bien a la mano de obra poco calificada, la cual logra obtener ingresos muy superiores a las líneas de pobreza y de indigencia (FAO, 2013), todo ello conlleva concretamente a que muchas personas dejen sus tierras y cultivos, para conseguir estabilidad económica y los recursos para ayudar a la subsistencia de sus familias, adhiriéndose a los proyecto de este cultivo.

No debe dejarse a un lado el impacto ambiental de los cultivos de palma de aceite y su empleo para la generación de biocombustibles, pues autores como George Monbiot, han señalado que productos como el biodiesel de palma africana, tiene como consecuencia el incremento del calentamiento global, lo que se explica por la destrucción de selvas tropicales, el drenaje de fuentes de agua y la oxidación de la tierra, lo que genera contaminantes como el dióxido de carbono, aunado al hecho de que los terrenos que se utilizan para el cultivo de la palma de aceite reemplazan otros propios de las regiones con los cuales se abastecen sus habitantes y las mismas familias que no tienen otra riqueza más que lo que sale como producto de sus unidades agrícolas. 


\section{Seguridad ALIMENTARIA}

La Organización de Naciones Unidas se ha pronunciado respecto a la seguridad alimentaria, precisando que es la disponibilidad de alimentos que un Estado debe proporcionar a su población para el aprovechamiento de los mismos; en palabras de la misma organización:

Existe seguridad alimentaria cuando todas las personas tienen en todo momento acceso físico y económico a suficientes alimentos inocuos y nutritivos para satisfacer sus necesidades alimenticias y sus preferencias en cuanto a los alimentos a fin de llevar una vida activa y sana (FAO, 2013).

\section{Dimensiones de la seguridad alimentaria}

Teniendo claro el concepto de seguridad alimentaria, es importante hacer alusión a sus dimensiones, para lo cual se traen a colación los siguientes conceptos, intrínsecamente relacionados con la misma.

Disponibilidad de alimentos. La existencia de cantidades suficientes de alimentos de calidad adecuada, suministrados a través de la producción del país o de importaciones (comprendida la ayuda alimentaria).

Acceso a los alimentos. Acceso de las personas a los recursos adecuados (recursos a los que se tiene derecho) para adquirir alimentos apropiados y una alimentación nutritiva. Estos derechos se definen como el conjunto de todos los grupos de productos sobre los cuales una persona puede tener acceso, en virtud de acuerdos jurídicos, políticos, económicos y sociales de la comunidad en que vive (comprendidos los derechos tradicionales, como el acceso a los recursos colectivos).

Utilización. Utilización biológica de los alimentos a través de una alimentación adecuada, agua potable, sanidad y atención médica, para lograr un estado de bienestar nutricional en el que se satisfagan todas las necesidades fisiológicas. Este concepto pone de relieve la importancia de los insumos no alimentarios en la seguridad alimentaria. 
Estabilidad. Para tener seguridad alimentaria, una población, un hogar o una persona debe tener acceso a alimentos adecuados en todo momento. No se debe correr el riesgo de quedarse sin acceso a los alimentos a consecuencia de crisis repentinas (por ejemplo, una crisis económica o climática) ni de acontecimientos cíclicos (como la inseguridad alimentaria estacional) (FAO, 2013).

\section{La seguridad alimentaria frente al derecho internacional según la FAO}

En el marco internacional, Colombia ha adquirido diferentes compromisos internacionales, dentro de los cuales se encuentra la garantía de derechos de contenido programático, pudiéndose circunscribir la seguridad alimentaria, para lo cual existen recomendaciones por parte de la ONU a través de dependencias como la ya mencionada FAO, la que ha precisado que para combatir el hambre, es necesario hablar de la agricultura y el desarrollo rural sostenible, que se pueden condensar de la siguiente manera:

La FAO para combatir el hambre combina la agricultura y el desarrollo rural sostenibles. En 1995, el Acuerdo sobre la Agricultura de la Organización Mundial del Comercio. Las normas del derecho internacional económico han ampliado el derecho internacional general, incidiendo en su diversificación y expansión, participando en lo que se denomina el proceso de fragmentación del derecho internacional general. Adicionalmente, algunos autores afirman que "el fenómeno de la globalización influye sobre el derecho internacional general" ya que "la universalidad de las reglas comunes entraña igualmente la especialización de ramas del derecho internacional y la autonomía relativa de sistemas jurídicos especiales concebidos en función de características propias de los ámbitos que regulan” (De León, 2013).

\section{La seguridad alimentaria frente al régimen colombiano}

En Colombia, es posible que una norma proteja al campesino para los cultivos de pancoger, como también es posible que proteja y respalde a los grandes productores del cultivo de palma de aceite, aun cuando su seguro enfrentamiento deje secuelas ocasionadas por los cultivadores de palma aceitera y en contra de los productores de 
alimentos que proporcionan la seguridad alimentaria al Estado colombiano como se presentará a continuación.

La Carta Política colombiana (1991) consagra:

Artículo 65. La producción de alimentos gozará de la especial protección del Estado. Para tal efecto, se otorgará prioridad al desarrollo integral de las actividades agrícolas, pecuarias, pesqueras, forestales y agroindustriales, así como también a la construcción de obras de infraestructura física y adecuación de tierras. De la misma manera, el Estado promoverá la investigación y la transferencia de tecnología para la producción de alimentos y materias primas de origen agropecuario, con el propósito de incrementar la productividad.

Acorde con esa situación se encuentra el artículo 334 superior, que preceptúa:

Artículo 334. La dirección general de la economía estará a cargo del Estado. Este intervendrá, por mandato de la ley, en la explotación de los recursos naturales, en el uso del suelo, en la producción, distribución, utilización y consumo de los bienes, y en los servicios públicos y privados, para racionalizar la economía con el fin de conseguir el mejoramiento de la calidad de vida de los habitantes, la distribución equitativa de las oportunidades y los beneficios del desarrollo y la preservación de un ambiente sano.

Las raíces del problema del hambre y la malnutrición no están en la falta de alimentos sino en la falta de acceso a los alimentos disponibles, por parte de los grandes segmentos de la población a causa de la pobreza.

De las normas transliteradas, se tiene que una política alimentaria nacional debe ser parte de una estrategia general de nutrición con seguridad alimentaria para los hogares de todas las personas como un objetivo central. Sobre ese aspecto se puede decir:

A la posible crisis mundial de alimentos, el Gobierno asegura que Colombia está blindada de la escasez de alimentos. Pero más allá de la situación internacional, expertos y campesinos consideran que hay otros factores que deben ser atendidos: la distribución de la tierra, la seguridad que dé garantías al derecho a la vida y a permanecer en el territorio; el desarrollo que les asegure los derechos a la educación, a la salud y al agua potable y, adicionalmente, inversión y créditos para la producción y comercialización de sus cosechas (Hechos del Callejón). 


\section{Respuesta académica de la seguridad alimentaria}

Resulta claro que la seguridad alimentaria es una obligación por parte del Estado, la que debe garantizarse en las mismas condiciones a toda la sociedad, pero a pesar de ello, el Gobierno ha generado una serie de políticas públicas encaminadas a fortalecer la producción de biocombustibles, tales como:

a) Garantizar el abastecimiento de hidrocarburos y sus derivados.

b) Competencia en los sectores de transporte, almacenamiento y distribución de combustibles líquidos derivados del petróleo.

c) Formación de precios de los energéticos mediante la adopción de esquemas de mercados.

d) Promover el desarrollo y la competencia en el mercado de biocombustibles y en el GNV.

e) Mejoramiento de la calidad de los combustibles en el país.

De acuerdo con lo anterior y sabiendo que el cultivo de la palma de aceite en Colombia provoca la erosión y muerte lenta de la tierra productiva para los productos de pancoger, el Estado toma la decisión de alternar de manera irresponsable los cultivos para alimentación de la población, junto con la producción de biocombustibles por el agotamiento lento del petróleo en el mundo, con el que contaremos más o menos hasta el año 2050.

La producción aumentada de los productos tales como, el maíz, la yuca, desarrollar la caña de azúcar, remolacha para producir alcohol carburante pensando en un proyecto con visión global nacional. Desarrollar la palma africana, jatropha e higuerilla para producir biodiesel. Aspirar a tener desarrolladas 3 millones de hectáreas en estos cultivos en los próximos 15 ańos. Se tendrían $400 \mathrm{MB} / \mathrm{D}$ en producción de biocombustibles. Haciendo a un lado los problemas reales sobre la producción de alimentos, para la seguridad alimentaria, el Ministerio de Minas y Energía, manifiesta que con los cultivos para la producción de biocombustibles, se generarían millones de empleos formales y de 3 a 4 millones de colombianos que tendrían su sustento en los biocombustibles (Ministerio de Minas, 2014). 


\section{Respuesta institucional al problema}

El Ministerio de Agricultura ha querido mostrar una excelente aceptación en la producción de biocombustibles frente a la soberanía alimentaria, en la que cada pueblo puede definir sus propias políticas agrarias y alimentarias de acuerdo con el desarrollo sostenible y de forma ecológica, también es cierto que la población campesina tiene derecho a decidir sobre su propio sistema alimentario y productivo. La seguridad alimentaria conjuntamente con la soberanía alimentaria, da la prioridad a las economías y mercados locales y nacionales al otorgar el poder a los campesinos y a la agricultura familiar, caso contrario con lo que sucede con la producción de los biocombustibles, que únicamente el Estado y unos pocos son los que tendrán la ganancia ocasional de su producción, dejando en desventaja a los pequeños productores de alimentos.

\section{Respuesta registral}

Colombia es un Estado con gran crecimiento en apoderamiento indebido de la tierra, no solo por los grupos insurgentes, sino por los mismos agentes del Estado. El Incoder, hoy la Agencia Nacional de Tierras, que es la entidad que debe repartir de manera equitativa la tierra entre la comunidad campesina pobre, a través de la UAF, no ha podido establecer una política clara respecto del apoderamiento de la tierra por parte de paramilitares, AUC y terratenientes que, a través de englobes, que es una forma de unir dos o más terrenos baldíos, los cuales están prohibidos por la Ley 160 de 1994 y junto a su Resolución 041 de 1994, en la cual se destina la distribución de la tierra en hectáreas de acuerdo a su ubicación, lo han logrado. Empero, el crecimiento económico en casos donde las cifras de concentración de capitales y bienes de producción como la tierra, está cada vez más concentrada en un menor número de propietarios, estaría favoreciendo un mayor incremento de los beneficios para un reducido sector de la población. En este esquema, el aumento per cápita se limita al sector que mayor participación tiene en la economía y no al conjunto de la población 7 .

7 En contexto con lo dispuesto, es importante anotar que "La soberanía concebida como la máxima expresión del ejercicio de autoridad de un Estado, parece atravesar una de sus más duras crisis al debilitarse la categoría del Estado-nación” (Blanco, 2013, p. 2013). 
La hipótesis de que quienes “jalonan” la economía pueden generar empleos al resto de la población y reducir así la pobreza, presenta vacíos que han puesto en duda su efectividad en la superación de situaciones críticas de injusticia e inequidad social y en el reconocimiento de otras visiones económicas, en la medida en que tal hipótesis no incluye variables como la sostenibilidad ambiental y cultural en países con una alta diversidad y fragilidad tanto natural como cultural. No considera la preexistencia de brechas estructurales de inequidad social e históricas, producto de la esclavización que requiere reparaciones, ni tampoco considera la existencia de sujetos colectivos especiales de derechos, que aspiran a visiones y opciones distintas de desarrollo basados en el respeto a la diferencia.

También presenta deficiencias en contextos donde se observa una alta violación de los derechos humanos y donde se evidencia la prevalencia de métodos basados en la fuerza y la violencia para resolver conflictos de interés económico.

Colombia ha optado por el impulso al crecimiento económico a pesar de las condiciones de conflicto, el desplazamiento forzado y el despojo de tierras y territorios ligados a intereses económicos, que ha afectado de manera desproporcionada a la población rural afrodescendiente, indígena y campesina en los últimos 15 años. El resultado de este contraste, conflicto y políticas de crecimiento económico, ha sido la permisividad de la concentración de tierras y la cada vez menor participación de los sectores campesinos y étnicos en los beneficios y oportunidades de desarrollo.

Ley 1579 de 2012. Estatuto de Registro, establece unos parámetros para el registro de baldíos por intermedio de la RUPTA, que es un formato de registro y protección por parte del Estado a estas tierras.

Ley 1448 de 2011. Llamada Ley de Tierras y de Víctimas, ha creado unas estrategias para establecer la forma de recuperación de las tierras bajo los siguientes parámetros:

- ¿Quién puede ser una víctima? Pueden ser víctimas las personas que individual o colectivamente hayan sufrido un daño de manera directa por hechos que guarden relación con el conflicto armado, siempre y cuando hayan ocurrido a partir de 1985 . 
- ¿Cómo iniciar el proceso para la reparación? Una vez incluido en el Registro Único de Víctimas es necesario activar las rutas de ayuda humanitaria, atención en salud y educación, protección, retornos, reubicaciones y de acceso a las distintas medidas de reparación, a las cuales pueden tener derecho las víctimas, de acuerdo con el daño sufrido en cada caso.

- ¿En qué consiste la reparación integral? 1. Rehabilitación. Incluye acciones de carácter jurídico, médico, psicológico y social. Con la rehabilitación, el Estado busca que las personas pueden poner de lado las dificultades que deja la guerra; que vuelvan a ser como antes y tengan las mismas posibilidades y deseos de seguir construyendo su futuro. 2. Indemnización. Las víctimas tienen derecho a una compensación económica por el daño sufrido. Los daños que genera el conflicto son irreparables y el dolor no se compensa con ninguna indemnización; sin embargo, el Estado colombiano expresa su reconocimiento a las víctimas, a través de una suma de dinero. 3. Satisfacción. Acciones que proporcionan bienestar y contribuyen a mitigar el dolor de las víctimas. El Estado tiene la obligación de restablecer la dignidad de las víctimas y difundir la verdad sobre lo sucedido a través de actos conmemorativos, reconocimientos y homenajes públicos, búsqueda de los desaparecidos, difusión de disculpas, investigación, juzgamiento y sanción de los responsables. 4. Garantías de no repetición. Los crímenes del pasado no se pueden volver a repetir. El Estado debe cambiar las condiciones que permitieron la violación de los derechos de millones de colombianos. 5. Restitución. A las víctimas se les deben restablecer sus derechos. Con la restitución de tierras, vivienda y empleo urbano y rural se busca restablecer las condiciones de vida de las víctimas. Para la restitución de tierras se estableció un procedimiento especial.

Ley 160 de 1994. Es la que demarca cuáles son los requisitos legales para la obtención adecuada de los baldíos distribuidos en todo el país, para ayudar no solo al campesino en general, sino a las comunidades afrodescendientes, comunidades indígenas y a personas de escasos recursos con las UAF, unidades agrícolas familiares, las cuales están enmarcadas en la Resolución 041 de 1994, de acuerdo a la ubicación del bien, para evitar la acumulación de tierras por los terratenientes o empresarios que disfrazan sus intereses personales con los de dar empleo de forma temporal a los 
pobladores para cultivar palma de aceite, caña de azúcar y maíz, entre otros, para la producción de biocombustibles sobre los cultivos de pancoger.

\section{OBSERVACIONES}

La suscrita autora quiere entrar a cuestionar el obrar de los entes de control y vigilancia del Estado en materia de tierras, en especial de la Superintendencia de Notariado y Registro (SNR), basada en su experiencia profesional no solo a la normatividad respecto de la adjudicación de baldíos, sino en las sentencias judiciales que supuestamente respaldan a quienes les ha sido adjudicada de manera legal la tierra y cómo, respaldados por la ilegalidad, la adquieren reconocidas empresas como Incauca y Riopaila Castilla.

Desde el punto de vista registral de la adjudicación de los bienes baldíos, también se ha venido presentando la acumulación de los mismos a través de la elaboración de escrituras públicas de compraventa de estos bienes en las que los terratenientes, llámense multinacionales, políticos, paramilitares o narcotraficantes, entre otros, han encontrado las diversas formas de adquirir predios del Estado, en las que por medio de la compraventa sin el lleno de los requisitos establecidos por la Ley 1579 de 2012, Estatuto de Registro de Instrumentos Públicos y de la no aplicación de la Ley 190 de 1994, estos documentos se siguen inscribiendo en las oficinas de registro, aun cuando no se han cumplidos los términos para trasladar la titularidad del derecho de dominio, esto es, las limitaciones que mediante la resolución de adjudicación del bien baldío se deja constancia de que existe un poder preferente de adquisición y este está dado como primera opción al Incoder (hoy Agencia Nacional de Tierras) y una vez por medio de acto administrativo, la entidad se pronuncia en su no interés en adquirir el bien; así el propietario podrá vender protocolizando en la escritura pública dicho acto administrativo, una vez verificado por el notario que ya superó el tiempo de limitación de la venta de acuerdo a la época de adjudicación 15, 10 o 5 años.

En el caso de Riopaila, que es una multinacional que ha venido acumulando bienes baldíos a pesar de que la ley prohíbe su acumulación, esta ha venido utilizando la tierra fértil de cultivos de pancoger para la creación de una planta destiladora de alcohol 
y se ha convertido en una empresa de bioenergía, la cual en estos momentos es uno de los proyectos más importantes del sector agroindustrial con un crecimiento anual del $25 \%$, dejando unas ganancias aproximadas de ocho billones de pesos; mientras que el campesino del común, no cuenta con el respaldo del Estado en la disminución de los impuestos del IVA para sus insumos y así poder aumentar la producción de los alimentos base de la seguridad alimentaria de la población colombiana.

La Ley 1450 de 2011, establece a través de juez constitucional defender los intereses de las comunidades campesinas sin apartarse del objetivo primordial de la política agraria, teniendo como objetivo principal al campesino y no dejarlo en un segundo plano para priorizar a las personas naturales o jurídicas ya sean nacionales o extranjeras.

En el caso de Riopaila, la SNR debió proceder y abrir los procesos disciplinarios correspondientes, tanto a los notarios que elaboraron las escrituras públicas de compraventa, como también a los registradores de instrumentos públicos que las registraron, por actuar en contravía a la Ley 160 de 1994, en la que se establece que no es posible la acumulación de baldíos en cabeza de persona natural o jurídica y que por tal motivo los funcionarios públicos deberán ser destituidos por actuar contrarios a la ley.

Como se puede observar en este caso en concreto, el mismo Estado ha permitido la violación a las normas promulgadas por el legislador, para beneficiar a unos cuantos, dejando de cumplir con un deber constitucional que es el de proteger a su población, manteniendo la seguridad alimentaria sobre el incremento de la producción de biocombustibles.

\section{Conclusiones}

La siembra de palma de aceite en Colombia, especialmente en las regiones del norte del país, ha conllevado a la destrucción de la biodiversidad del ecosistema, a la fauna y la flora, afectando a diferentes comunidades por ser un monocultivo que se ha implantado a través de mecanismos violentos, a la invasión de tierras y ocasionando daños ambientales, que se materializaron a través de graves violaciones a los derechos humanos, hechos perpetrados por grupos paramilitares. 
Así como lo dijo hace unos años Alfredo Molano, la destrucción del medio ambiente y su explotación van de la mano de la violencia, lo que se evidencia no solo en masacres que quedarán en la memoria de los colombianos, como la de Las Bananeras, sino por hechos graves de desplazamientos forzados, homicidios y los altos índices de pobreza, que se agravan porque los hogares campesinos no tienen forma de cultivar para satisfacer una de sus necesidades básicas, su alimentación. Situaciones que generalmente tuvieron lugar en el Chocó o en el Darién, donde aproximadamente 20000 campesinos fueron despojados de sus tierras.

Pero más allá de la grave situación mencionada, lo cierto es que la producción de biocombustibles a través de la palma de aceite va aparejada de un grave daño al medio ambiente, donde se benefician las megaempresas pero no las poblaciones, pues para mantener los costos laborales, las condiciones de trabajo son arduas y los salarios ofrecidos no llegan siquiera al salario mínimo legal vigente. Además, se han perdido muchas hectáreas de bosques tropicales biodiversos, por los incendios provocados. En otros países como Indonesia, se determinó que en 1997 estos incendios fueron provocados por grandes empresas productoras de la mencionada palma, aunado el daño ambiental a que el territorio donde se siembra palma se convierte en un desierto, afectando incluso humedales.

El contexto anterior se ve agravado con un hecho fundamental que no ha sido tomado en cuenta por las autoridades, como es la apropiación de tierras donde las poblaciones agrícolas tiene sus cultivos con los cuales alimentan a sus familias y comercian, sin que puedan siquiera a través de ese trabajo, satisfacer esta necesidad básica, por la invasión generada por el auge de la palma de aceite en la producción de biocombustibles.

Las leyes establecidas por el Estado colombiano para la defensa y distribución de las tierras en Colombia, no responden ni abarcan todos los problemas en materia jurídica respecto de la posesión legitima de la tierra, ni de los cultivos que se siembran en ella, ya que las diferentes normas que regulan tanto a las unas como a las otras, muchas veces se aplican de manera subjetiva por quien ejerce el poder judicial, en muchas ocasiones acomodando los fallos a través de interpretaciones pobres de la normatividad que es clara y precisa para cada caso en especial, aumentando la falta de seguridad jurídica y llegando a finalizar procesos de manera injusta y a veces dejando 
impune la violación de los que tienen sus derechos legítimos en la adquisición de la tierra.

Las leyes de adjudicación de tierras que tienen una destinación específica para cultivos de pancoger y de autosostenimiento, son para darle estricto cumplimiento y no para interpretarlas y ajustarlas según la conveniencia de quienes las quieren obtener para otros fines, como en el caso de la producción de biocombustibles y así de manera injustificada, privilegiar un derecho disfrazándolo con otras actividades de producción y demostrar una generación de empleo temporal para la región afectada.

La producción de combustibles ecológicos no puede coexistir como un derecho esencial sobre la seguridad alimentaria, sino como una alternativa que no sobrepase los límites de importancia sobre los cultivos de pancoger, que son los que van a asegurar a la población, por parte del Estado, la alimentación necesaria para cada grupo familiar, siendo un deber y un compromiso del Estado garantizar a través del trabajo interinstitucional y una participación activa de la población, ya sea por medio de la creación de unos espacios entre funcionarios y comités creados por las autoridades locales para contribuir a una búsqueda efectiva para garantizar la seguridad alimentaria.

Para lograr la seguridad alimentaria, el Estado colombiano deberá esforzarse en establecer unos parámetros serios para garantizar un suministro alimentario seguro y respaldado nutricionalmente por unas políticas establecidas por él mismo, como el objetivo principal para que los hogares tengan un grado razonable de estabilidad en el suministro alimentario, con suficientes alimentos en cada hogar y poder así satisfacer las necesidades primarias de todos.

El Estado debe establecer unos lineamientos jurídicos válidos para evitar que se siga violando de manera indiscriminada el artículo 72 de la Ley 160 de 1994 y que la Agencia Nacional de Tierras (ANT) adjudique los baldíos a campesinos de escasos recursos y no a entidades como Incauca Castilla Colombia, la cual adquirió más de 43000 hectáreas de manera irregular a través de 27 entidades unipersonales, más conocidas como SAS. 
Es probable que se pueda llegar a garantizar en Colombia la seguridad alimentaria, siempre y cuando exista la voluntad del Estado en individualizar la tierra de manera equitativa y apoyar a la población campesina más pobre, generando unas políticas de respaldo económico en cuanto a que los insumos que se necesitan para sus cultivos, no estén gravados con el IVA o por lo menos estén subsidiados por el Estado, como lo hizo con los cultivadores de palma de aceite por un período de 10 años, entre el 2004 y el 2014.

El Estado a través del Ministerio de Agricultura, deberá utilizar la tecnología de avanzada para promover los productos que los campesinos cultivan y se puedan hacer transacciones entre comunidades por Internet, asumiendo a través de subsidios, los costos del traslado de los productos y que la otra parte pueda ser asumida por el campesino.

Como una conclusión final, el Estado debe mantener por encima de todo cultivo que enriquezca a unos cuantos empresarios, los cultivos de pancoger para garantizar la seguridad alimentaria del pueblo colombiano.

El Estado, a través de un trabajo interinstitucional, deberá procurar que la justicia y quienes la representan, como jueces, fiscales y magistrados, tengan una unidad de criterio, no solo en sus sentencias, sino en la revocatoria de las resoluciones de adjudicación de terrenos que son determinados como baldíos a través de la ANT en cualquier tiempo, sin la autorización del titular inscrito. 


\section{REFERENCIAS}

ACNUR. (2004). El cultivo de palma africana en el Chocó. Legalidad ambiental, territorial y derechos humanos. Bogotá D. C., Colombia: ACNUR.

Blanco, C. (2013). Aproximación a la noción de soberanía estatal en el marco del proceso andino de integración. Revista Republicana, 2(15), 91-103. Recuperado de http://ojs. urepublicana.edu.co/index.php/revistarepublicana/article/view/23/21

Blanco, C. (2017). Condiciones de cohesión entre la comunidad andina (CAN) y la descentralización territorial colombiana. Revista Republicana, 2(23), 67-92. DOI: http:// dx.doi.org/10.21017/Rev.Repub.2017.v23.a31. Recuperado de http://ojs.urepublicana. edu.co/index.php/revistarepublicana/article/view/406/359

Cadena, W. (2018). El Hermano hombre de Fernando Soto Aparicio. Revista Via Inveniendi et Iudicandi, Vol. 13(1), 237-262. DOI: http://dx.doi.org/10.15332/s19090528.2018.0001.09. Recuperado de http://revistas.usantotomas.edu.co/index.php/viei/ article/view/4273/4050

Comisión de Interlocución del Sur de Bolívar, Centro y Sur del Cesar, CISBCS. (2015). Por presencia de paramilitares al servicio del latifundio, peligra la vida de comunidad de Terraplén, Cesar. [Mensaje en un blog]. Ojos para la Paz. Recuperado de http://ojosparalapaz-colombia.blogspot.com.co/2015/04/por-presencia-de-paramilitares-al.html

Cortés Villafrádez, R. A., Moreno, D., Albornoz, D., y Poveda, A. (2011). Análisis del impacto de la política de biocombustibles en la producción del aceite de palma y la estabilización del precio interno en Colombia. Civilizar de Empresa y Economía, 3(5), 81-97.

De León, C. (2013). La realización entre la globalización y el derecho internacional económico. Academia, 45-67.

Delgado Munévar, W. G. (2004). TLC Colombia-Estados Unidos y su incidencia en el sector agricola. Eumed, 35-55.

Elias Caro, J. E. (2011). La masacre obrera de 1928 en la zona bananera del MagdalenaColombia. Una historia inconclusa. Andes, 22, 48-74.

FAO. (2013). El papel de la agricultura en el desarrollo de los paises. Washington: ONU. 
Fedepalma. (2007). 45 ańos de institucionalidad gremial del sector palmero colombiano. Revista Palmas.

Galeano, E. (1997). Las venas abiertas de América Latina. Montevideo, Uruguay: FMMEDUCACION.

Grueso, L. (2014). Crecimiento económico, conflicto y derechos colectivos en el sector rural colombiano. Afrodescendienes - Naciones Unidas.

Hechos del Callejón. (s. f.). Seguridad alimentaria en Colombia: una preocupación campesina. [Mensaje en un blog]. País Real. Recuperado de http://pais-real.blogspot.com. co/2010/09/seguridad-alimentaria-en-colombia-una.html

Hurtado, M. (2017). Crisis de la forma jurídica y el despertar antisistémico: una mirada desde el pluralismo jurídico de las Juntas de Buen Gobierno (JBG). Revista IUSTA, 2(47), 19-33. DOI: http://dx.doi.org/10.15332/s1900-0448.2017.0047.01. Recuperado de http://revistas.usta.edu.co/index.php/iusta/article/view/3810/3749

Kucharz, T. (2005). La palma africana en Colombia. El Ecologista 44, 37-47.

Ley No 160. (1994). Por la cual se crea el Sistema Nacional de Reforma Agraria y Desarrollo Rural. Diario Oficial No 41.479 de la República de Colombia, Bogotá D. C., Colombia, 5 de agosto de 1994.

López Hernández, D. (2012). Disponibilidad de alimentos básicos en Colombia: ¿producción nacional o importaciones? Universidad Nacional de Colombia, 34-65.

Machado, A., y Vivas, J. (2009). Ensayos para la historia de la política de tierras en Colombia. De la colonia a la creación del Frente Nacional. Bogotá D. C., Colombia: Editorial Gente Nueva.

Menco Rivera, D. (2011). Palma aceitera y la seguridad alimentaria en María La Baja, Montes de María. 2000-2008. Observatorio de la Economía Latinoamericana, (157).

Ministerio de Minas y Energía. (2014). Los biocombustibles. Bogotá D. C., Colombia: Minminas.

Molina, S. (2017). ¿Qué busca el Estado con una política pública? Dinámica de las políticas públicas y los valores entre las instituciones estatales. Revista IUSTA, 1(46), 63-84. Recuperado de http://revistas.usta.edu.co/index.php/iusta/article/view/3526/3416 
Ocampo Valencia, S. (2009). El caso de la palma de aceite. Colombia Internacional, (70), 169-190.

Osorio, J. (2017). Prácticas de los abogados en formación en los consultorios jurídicos. Revista Via Inveniendi et Iudicandi, 12(1), 119-148. Recuperado de http://revistas.usantotomas.edu.co/index.php/viei/article/view/3560/3448

Proyecto Planeta Paz. (2012). La cuestión agraria en Colombia: tierra, desarrollo y paz. Bogotá D. C., Colombia: Planeta Paz.

Rey Sabogal, C. (2013). Análisis espacial de la correlación entre cultivo de palma de aceite y desplazamiento forzado en Colombia. Cuadernos de Economía, 683-719.

Reyes, R. (1990). La economía extractiva en la Amazonia colombiana 1850-1930. Bogotá D. E., Colombia: Tropenbos.

Salcedo, S., y Guzmán, L. (2014). Agricultura familiar en América Latina y el Caribe. Santiago de Chile, Chile: Organización de Naciones Unidas.

Sánchez Mejía, H. R., y Santos Delgado, A. (2014). Estado, innovación y expansión de la agroindustria azucarera en el valle del río Cauca (Colombia), 1910-1945. América Latina en la historia económica, 37-56. 